D urante una excursión realizada al Parque Nacional "Pico de Tancítaro", al explorar en la base del Cerro Piedra del Horno, se encontró entre las peñas una planta muy pequeña y escasa del género Sedum. Al identificarla coincidió con Sedum clavifolium Rose. Esta especie era conocida sólo de la región de la cañada de Alcalican (Clausen, 1959; Jacobsen, 1978), en los municipios de Tlalmanalco y Amecameca en el Edo. de México, en la vertiente oeste del volcán Iztaccíhuatl (Calderón y Rzedowski, 2001).

Sedum clavifolium fue descrito en 1911 por Rose a partir de material proveniente de la colecta No. 1681 de Carl Albert Purpus (US 399,592), realizada en noviembre de 1905 , en rocosidades ubicadas más arriba del límite de la vegetación arbórea del Iztaccíhuatl (Clausen, 1959). Las plantas pertenecientes a esta especie fueron recolectadas de nuevo hasta que Clausen la encontró en 1955, después de una intensa búsqueda por ambos lados de la barranca de Alcalican, el valle de Milpulco y valles aledaños, asî como en la cañada de Texantilia. Las plantas fueron halladas por debajo del límite de la vegetación arbórea, en lugares parcialmente sombreados sobre acantilados de conglomerados, con orientación este, este-noreste y noreste, cerca de la base de Las Agujas, uno de los "Picos Centinelas", en el lado norte de la barranca de Alcalican, Edo. de México. Durante su viaje realizado en 1955, Clausen muestreó poblaciones con más de 50 plantas en un área de $420 \mathrm{~m}^{2}$, en el intervalo altitudinal de 3,700 a $3,721 \mathrm{~m}$, en sitios con drenaje de moderado a excesivo y con un $\mathrm{pH}$ de entre 5.4 y 5.8 en el sustrato (Clausen, 1959).

La descripción de Sedum clavifolium realizada por Clausen (1959) coincide con la de las plantas observadas en la nueva localidad (figura 1). Éstas se caracterizan por ser plantas perennes de 1 a $3 \mathrm{~cm}$ de alto, hemicriptofitas y con rizomas ramificados. Sus hojas son

\title{
Sedum Clavifolium Rose (Crassulaceae), NUEVO REGISTRO PARA LA FLORA DE MichOACÁN, MÉXICO
}

\author{
Ignacio García R.
}

Centro Interdisciplinario de Investigación para el Desarrollo Integral Regional (CIIDIR-IPN- Michoacán), Justo Sierra No. 28, Jiquilpan, Michoacán, C.P. 59510. Correo-e: igarciar@ipn.mx

oblanceoladas o espatuladas y están dispuestas en rosetas; la base de las hojas del tallo floral son cortamente espolonadas. Las cimas tienen entre una y tres flores dispuestas sobre pedicelos cortos; los sépalos son oblanceolados, moteados de rojo, y los pétalos son ovados, de color blancoverdoso, con líneas o motas color rosa, rojo o púrpura; el color de los nectarios es rojo o púrpura (Clausen, 1959).

Jacobsen (1978) indica que Sedum clavifolium es la única especie de la serie Clavifolia Berger, dentro de la sección Sedum (Seda genuina Koch). Dicha sección incluye hierbas perennes y anuales que carecen de un verdadero rizoma, que por lo general son siempre verdes y usualmente poseen tallos estériles ascendentes, colgantes y cespitosos; en ella están contenidas la mayoría de las especies del género Sedum, las cuales se agrupan en 27 series naturales (Jacobsen, 1978).

El registro de Sedum clavifolium en el Cerro Tancítaro, Michoacán, amplía significativamente el área de distribución de la especie hacia el occidente sobre el Eje Volcánico Transversal. Este hallazgo confirma la anotación de Clausen (1959), respecto a que las especies del género Sedum del Eje Volcánico Transversal tienen generalmente una distribución geográfica limitada, y que entre ellas hay un elevado número de endemismos. En esta región la migración de las poblaciones es aparentemente lenta y usualmente alcanzando distancias cortas, por lo que las especies invaden nuevos sitios con lentitud. Por otra parte, el desarrollo de picos volcánicos elevados en esta región ha creado una serie de condiciones ambientales diversas y disyuntas, lo que al parecer tiene una importancia primordial en la evolución de este grupo de plantas.

El material recolectado en el Cerro Tancítaro (figura 1) (I. García, J. A. Pérez de la Rosa, A. Rodríguez y L. Catedral, 1 de septiembre de 2002, No. 6,140, depositado en el Herbario CIMI), en la base del Cerro Piedra del Horno a un elevación de 3,300 m, es rupícola y se desarrolla en laderas con orientación norte-noreste, donde crece junto con otra Crassulaceae, Villadia batesii (Hemsl.) Baehi et Macbr. La vegetación corresponde a un bosque de coníferas con Pinus hartwegii Lindl. y Juniperus monticola Martínez. En el estrato herbáceo son comunes Tigridia alpestris var. obtusa Molseed (endémica de este lugar), así como Sisyrinchium pringlei B.L.Rob. et Greenm., Carex turbinata Liebm., Calamagrostis valida Sohns, Luzula gigantea Desv. y Dahlia scapigera (A. Dietr.) Knowles et Westc., entre otras (García et al., 2002). 
Según Clausen (1959), el taxon más cercano a Sedum clavifolium es $S$. clavatum R.T.Clausen (Clausen, 1975), especie conocida del río Tenancingo en el Estado de México. Sin embargo, ambas difieren porque esta última es bienal, produce cormos en lugar de rizomas y produce semillas de menor tamaño. Sedum minimum Rose y S. cormiferum R.T.Clausen también difieren de $S$. clavifolium por ser bienales; además, la primera carece de hojas arrosetadas, presenta cormos y sus pétalos blancos tienen una banda roja ancha por debajo de la parte media; a su vez, la segunda tiene hojas más anchas y presenta un mayor número de flores (Clausen, 1959). Por otro lado, S. clavifolium difiere de $S$. longipes Rose y $S$. pentastamineum R.T.Clausen, ambas perennes, en que éstas tienen tallos largos colgantes, carecen de rizomas y sus flores son más grandes.

Análisis cariotípicos posteriores revelaron los siguientes números cromosómicos: Sedum minimum, $\mathrm{n}=$ 10 - 11 (Clausen, 1981); S. clavifolium $\mathrm{n}=34-38 ;$ S. longipes $\mathrm{n}=19 ; S$. clavatum $\mathrm{n}=34 ; \mathrm{y} S$. pentastamineum $\mathrm{n}=19$ (Uhl, 1985). Esta información apoya la estrecha relación entre Sedum clavifolium y $S$. clavatum y coincide con la opinión expresada inicialmente por Clausen (1959). A pesar del desarrollo reciente y uso masivo de técnicas de marcadores moleculares, todavía no se dispone de información actualizada sobre las relaciones filogenéticas entre las especies de la sección Sedum. Como sucede en el caso de numerosos géneros complejos, hace falta mucho trabajo de exploración, gabinete y laboratorio para poder obtener una mejor comprensión de los orígenes y las relaciones evolutivas de las especies endémicas de México.

Ésta es la segunda especie del género Sedum que ha sido localizada dentro del Parque Nacional Pico de Tancítaro. La otra especie corresponde a Sedum neovolcanicum Pérez-Calix et I. García, recientemente publicada como especie nueva para la ciencia, la cual es originaria de este lugar y de la región de los volcanes Nevado de Colima y de Fuego en el estado de Jalisco, en la porción occidental del Eje Neovolcánico Transversal (PérezCalix y García, 2002).

Las plantas de Sedum clavifolium son raras y poco evidentes (debido a su pequeño tamaño). Su población silvestre en el Cerro Tancítaro también es reducida. Sin embargo, se considera que en dicha localidad existen las condiciones apropiadas para su buen desarrollo, por lo que no sería raro que al ampliar las exploraciones en esta área se incremente el número de ejemplares de esta diminuta planta.

\section{Agradecimientos}

A la COFAA del Instituto Politécnico Nacional por su apoyo en este tipo de investigaciones. A Emmanuel PérezCalix por la lectura crítica y sugerencias. A los revisores anónimos, así como a Jorge Meave y Eduardo A. Pérez-García, por sus comentarios, sugerencias e ideas. A Jorge A. Pérez de la Rosa, Aarón Rodríguez y Luis Catedral por su compañía en trabajo de campo.

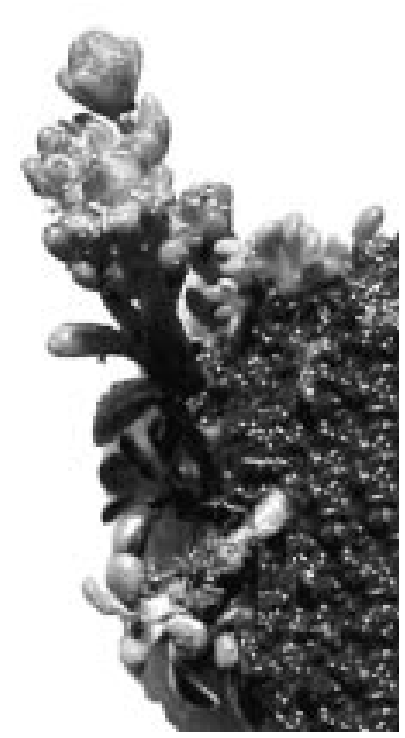

Figura 1. Sedum clavifolium Rose, proveniente de cerca de la base del Cerro Piedra del Horno, Parque Nacional Pico de Tancítaro, Michoacán.

\section{Literatura citada}

Calderón de R. G. y Rzedowski J. Eds. 2001. Flora Fanerogámica del Valle de México. pp. 223-225. Instituto de Ecología, A.C. Centro Regional del Bajío y Comisión Nacional para el Conocimiento y Uso de la Biodiversidad, Pátzcuaro, Michoacán.

Clausen R.T. 1959. Sedum of the TransMexican Volcanic Belt: an Exposition of Taxonomic Methods. Cornell University Press, Ithaca, N.Y.

Clausen R.T. 1975. Sedum of North America North of the Mexican Plateau. Cornell University Press, Ithaca, N.Y.

Clausen R.T. 1981. Variation of Species of Sedum of the Mexican Cordilleran Plateau. Editado por el autor, Ithaca, N.Y.

García R. I., Nava V.J., Flores R.R.E., Cházaro B.M., Machuca N.J.A. y del Río N.E. 2002. Flora del Parque Nacional Pico de Tancítaro, Michoacán. Serie Fuentes para el Conocimiento Natural de Michoacán, No. 1. Gobierno del Estado de Michoacán de Ocampo, Morelia, Michoacán.

Jacobsen H. 1978. A Handbook of Succulent Plants. Vol. 2 (Reprint), pp. 762776, Blandford Press, Poole, Dorset, Reino Unido.

Pérez-Calix E. y García I. 2002. Sedum neovolcanicum (Crassulaceae), una especie nueva originaria del centro occidente de México. Acta Botanica Mexicana 58:57-62.

Uhl H.C. 1985. Chromosomes of Mexican Sedum V. Section Sedum and subgenus Sulcus. Rhodora 87:381-423.

Fecha de recepción: 16 de julio de 2003

Versión corregida: 29 de octubre de 2003

Aceptado: 5 de noviembre de 2003 